\title{
Transferencia de blastocisto: ¿Un paso importante para aumentar las tasas de implantación y embarazo en un programa de FIV? (Reporte del primer embarazo en Colombia-Centro Colombiano de Fertilidad y esterilidad)
}

\author{
Carolina Lucena BS; Angela Arango BS; Andrés Lucena MD; Jaime Ferro MD; Juan Carlos Mendoza MD; Hernando \\ Ruiz MD; Zulma Suárez BS; María Emilia Pinzón; Elkin Lucena MD
}

\begin{abstract}
RESUMEN
Presentamos el primer embarazo logrado en nuestro centro de reproducción asistida (CECOLFES) obtenido después de la transferencia de Blastocistos cultivados en medio de Gardner en una paciente de 32 años, con infertilidad secundaria de 8 años de evolución.

La paciente fue estimulada con supresión GnRH-a y Gonadotrofina menopáusica humana, realizando la transferencia de 2 blastocistos el día 5 post-aspiración folicular, obteniéndose un embarazo clínico.
\end{abstract}

PALABRAS CLAVES: Transferencia, blastocisto, primer embarazo.

SUMMARY

OBJECTIVE: To present the first pregnancy obtained after transfer of two blastocyst embryo in our reproduction center in Colombia.

DESIGN: Case report.

Setting: Private practice with University Academic Activity.

PATIENT: A32 years old with secundary infertility of 8 years was treated. Her first pregnancy was an spontaneus abortion an the second was an ectopic pregnancy with surgycal treatment (Right Salpingectomy).

INTERVENTIONS: Down regulation with leuprolide acetate followed by HMG 300UI daily for ovulation induction was used, Transvaginal oocyte retrieval, embryo culture in Gardner's medium and transfer in day 5 after oocyte retrieval was done.

RESULT(S): Clinic pregnancy with one intrauterine gestational sac and embriocardia.

CONCLUSION(S): This case shows that we are able to obtain pregnancies in IVF after blastocyst culture in a Gardner's medium.

Blastocyst transfer is a good alternative for patients with previous IVF failures.

KEY WORDS: Transfer, blastocyst, first pregnancy.

\section{Introducción}

Dentro de las limitantes en un programa de fertilización in vitro encontramos las bajas tasas de implantación y embarazo que se consiguen al transferir embriones generalmente en su segundo o tercer día de desarrollo (10-15\% por embrión transferido). Con el perfeccionamiento en los medios de cultivo se han conseguido

BS: Ciencias Básicas

MD: Médico embriones en etapa de BLASTOCISTO, los cuales al ser transferidos, mejoran las tasas de implantación y embarazo (60 a 63\%, Gardner 1997 - Buster 1995); a su vez disminuyen el número de embriones requeridos por transferencia y también la posibilidad de embarazos múltiples, (Sólo 2 blastocistos por transferencia).

El embrión en etapa de clivaje se caracteriza por niveles relativamente bajos de biosíntesis y una capacidad limitada para utilizar la glucosa como fuente de energía. En contraste, las tasas de biosíntesis en la etapa posterior a la compactación aumentan, junto con la capacidad respiratoria y la habilidad para utilizar la 
glucosa (Rieger, 1984; 1992; Gardner, 1998). Por consiguiente en lo que se refiere a la fisiología embrionaria, conviene considerar el período previo a la implantación por lo menos en dos fases: antes y después de la compactación e iniciación de la activación del genoma. Esta división del período preimplantación es importante al pensar en cambiar las formulaciones de los medios de cultivo.

En cuanto a la composición de los medios, sabemos que la glucosa en altas concentraciones en las primeras etapas de división es la causante del retardo o la interrupción del desarrollo del embrión. A la luz de este efecto nocivo que afecta a los embriones en medio simple de cultivo, existe una tendencia cada vez mayor a disminuir la concentración de glucosa hasta la etapa de 8 células y aumentar su concentración después de ésta para lograr el desarrollo del embrión humano. Pero una vez se han dispersado las células del Cúmulos, el embrión queda expuesto a la glucosa presente en el oviducto del tracto genital femenino, aunque en concentraciones pequeñas, por lo tanto la glucosa adquiere cada vez más importancia una vez activado el genoma embrionario y cuando aumentan los niveles de biosíntesis.

Se propone que los aminoácidos son uno de los reguladores más importantes del desarrollo en la etapa previa a la implantación y por lo tanto, constituyen elementos claves dentro del medio de cultivo. Se ha demostrado que incluir aminoácidos específicos alivia los denominados Bloqueos de cultivo al desarrollo del embrión (Kane y Foote, 1970, Conejo; Bavister et al. 1993, Hamster; Kishi et al, 1991, ratas; Gardner et al. 1994, ovejas; Gardner, 1994, vacas). Al mismo tiempo se determinó que los aminoácidos no esenciales y la glutamina estimulan la formación del blastocele, aumentan el número de células del trofoectodermo y elevan las tasas de eclosión de la zona pelúcida.

Todo esto indica que es importante mantener y cultivar a los oocitos y los embriones en presencia de aminoácidos no sólo antes de la compactación sino después de ésta.

De los datos obtenidos a través de los estudios antes mencionados se desprende el hecho de que los medios de cultivo convencionales no son adecuados para cultivar embriones durante períodos prolongados hasta la etapa de blastocisto, especialmente cuando estos medios son suplementados con suero. A la luz de los datos presentados se han formulado dos medios para el cultivo del zigoto humano hasta la etapa de blastocisto: (Barnes et al 1995; Gardner y Lane 1997).

En un estudio piloto con estos medios (Gardner y Lane 1997) la media de desarrollo de los blastocistos a los cinco días de inseminación fue de $66 \%$, al transferir en promedio 2.75 blastocistos se obtuvo una tasa de implantación del $45 \%$ culminando con tasas de embarazos en curso del $63 \%$ a la fecha (Gardner et al 1998).

Aunque estos estudios son alentadores, se necesitan estudios clínicos prospectivos extensos para validar la eficacia de la transferencia de los blastocistos después de desarrollarlos en estos medios.

\section{Caso clínico}

Paciente de 32 años con infertilidad secundaria de 8 años de evolución, con antecedente de un aborto espontáneo y un embarazo ectópico que requirió salpingectomía derecha. Ingresa al programa de FIV después de tratamientos médicos convencionales sin lograr embarazo.

Se inicia protocolo de estimulación con $\mathrm{GnRHa}$ (Lupron $\left.\operatorname{Depot}^{(8)}\right), 3.75 \mathrm{mg} 1 \mathrm{M}$ administrado el primer día del ciclo. El día 28 post GnRHa se inicia estímulo con gonadotropina menopáusica humana (hMG, Humegon ${ }^{\sqrt{B}}$ ) 300 UI / IM día. Un total de 32 ampollas de hMG de 75 UI fueron utilizadas hasta el día de la aplicación de gonadotropina coriónica humana (HCG, Profasi ${ }^{\sqrt{ }}$ ) 10.000 UI IM. El pico máximo de estradiol fue de $2525 \mathrm{pg} / \mathrm{ml}$. El seguimiento folicular ecográfico transvaginal mostró 9 folículos mayores de 17 $\mathrm{mm}$. El perfil uterino realizado con Doppler color el día previo a la transferencia fue de 16 , lo que significa una adecuada receptividad endometrial (Dickey 1997).

Se realiza la aspiración por vía ecográfica transvaginal 34 horas después de administrada la HCG obteniéndose 8 oocitos de los cuales 7 fertilizaron y 4 llegaron a etapa de blastocisto cultivados en el medio de Gardner. Se transfieren 2 embriones así: Un blastocisto $\mathrm{C}$ y un blastocisto $\mathrm{A}$ a las 110 horas post aspiración folicular.

La suplementación de la fase lútea se realiza con progesterona y $\mathrm{HCG}$.

Los datos hormonales obtenidos el día 12 postransferencia fueron:

Progesterona mayor de $40 \mathrm{ng} / \mathrm{ml}$, Estradiol en 3269 $\mathrm{pg} / \mathrm{dl}$ y b-HCG en $243 \mathrm{UI} / \mathrm{ml}$.

El día 30 postransferencia se observa por ultrasonografía transvaginal un saco gestacional tónico lo cual confirma embarazo clínico, y el día 40 se visualiza embriocardia.

\section{Discusión}

Entre las posibles ventajas del cultivo y transferencia de Blastocistos se encuentran:

- Sincronización del embrión con el tracto reproductor femenino.

- Evaluación de la viabilidad del embrión antes de la transferencia, con lo cual sólo los mejores serán transferidos.

- Cuantificación de marcadores embrionarios verdaderos y no de aquellos heredados del oocito.

- Aumenta el tiempo disponible entre la biopsia del embrión en etapa de clivaje y la transferencia en los que se requiera diagnóstico genético preconcepcional.

- Facilita la utilización de la biopsia del trofoectodermo para tamizaje de enfermedades genéticas.

Hoy en día uno de los problemas ocultos y hacia donde están encaminados todos los estudios es la IMPLANTACION, porque se ha llegado a manejar el problema ovulatorio, el factor masculino (casi solucionado con el ICSI) pero poco conocemos del endometrio y sólo tenemos mediciones indirectas hormonales y ultrasonográficas para acercarnos al momento ideal de transferencia ya que normalmente la efectuamos en forma prematura. Esto podría ser la causa de las bajas tasas de implantación. 
Transferimos embriones de cuatro células momento en el cual debería estar en la trompa y no en el endometrio donde el $\mathrm{pH}$ es diferente.

Los datos actuales acerca de la transferencia de mórulas cavitantes y/o blastocistos al cuarto o quinto día del desarrollo indican que estos embriones presentan una tasa de implantación más alta (Huisman et al, 1994; Olivennes et al, 1994; Ménezo y Ben Khalifa, 1995). Para los blastocistos se han informado tasas de implantación dos veces mayores a las obtenidas con embriones en clivaje (Scholter y Zeilmaker, 1996). Buster en 1985 transfirió individualmente a las pacientes receptoras blastocistos humanos desarrollados in vivo y lavados del útero; las tasas de implantación y embarazo en el estudio fueron del $60 \%$ por blastocisto transferido.

También existe la posibilidad de lograr desarrollo de blastocistos con cocultivos con tasas similares de implantación, pero con mayores problemas para lograr y mantener los cocultivos. Por eso con el mejoramiento de los medios de cultivo y el desarrollo embrionario al conocer más de cerca su físiología, el blastocisto deberá ser el protagonista en los próximos años esperando mejorar las tasas de implantación.

\section{Conclusiones}

En pacientes en las cuales se considera que el factor principal de infertilidad es una alteración de la implantación, la transferencia de blastocistos puede ser una alternativa de tratamiento.

La transferencia de blastocistos por sí sólo mejoraría la eficiencia general de la fertilización in vitro en seres humanos, permitiendo reducir el número de embriones requeridos para lograr el embarazo y minimizando también el número de nacimientos múltiples.

La posibilidad de escoger blastocistos más viables para la transferencia con base en la cuantificación no invasiva del metabolismo (midiendo $\mathrm{pH}$ o sustancias obtenidas del metabolismo) debería culminar en tasas todavía mayores de implantación y embarazo por cada blastocisto transferido.

Es cierto también que no hay muchos estudios y sería razonable para llegar a conclusiones tan importantes para las parejas, contar con estudios prospectivos con mayor número de casos.

Se ha logrado el primer embarazo clínico en Colombia con la transferencia de blastocistos.

\section{BIBLIOGRAFIA}

1. Dickey, R. Doppler ultrasound investigation of uterine and ovarian blood flow in infertility and early pregnancy. Hum Reprod 1997; 3 : 467-503.

2. Gardner, DK. and Lane, M. Culture and selection of viable blastocysts: a feasible proposition for human IVF?. Hum Reprod. 1997; 3: $367-$ 382.

3. Barnes, FL., Crombie, A. And Gardner, DK. et al. Blastocyst development and birth after in-vitro maduration of human primary oocytes, intracytoplasmic sperm injection and assisted hatching Hum Reprod. 1995; 10: 3243-3247.

. Bavister, BD. and McKierman, SH. Regulation of hamster embryo development in vitro by amino acids. In Bavister, BD. (ed.), Preimplantation Embryo Development. Springer Verlag, New York, 1993; 57-72.

5. Biggers, JD., Bell, JE. and Benos, DJ. The mamalian blastocyst: transport funtions in a developing epithelium. Am J. Physiol. 255 (Cell Physiology 24), 1987; C419-C432.

6. Kane, MT. and Foote, RH. Culture of two- and four-cell rabbit embryos to the expanding blastocyst stage in synthetic media. Proc. Soc. Exp. Biol. Med., 1970; 133: 921-925.

7. Kishi, J., Noda, Y., Narimoto, K.et al. Blockto development in cultured rat l-cell embryos is overcome using medium HECM-1. Hum Reprod., 1991; 6: 1445-1448.
8. Huisman,GJ., Alerda, A.Th., Leerentvelt, RA. et al. A comparison of in vitro fertilization results after embryo transfer after 2, 3, and 4 days of embryo culture. Fertil. Steril. 1994; 61: 970-971.

9. Ménézo, YJ. and Ben Khalifa, M. Cytogenetic and cryobiology of human cooculture embryos: a 3-year experience. J Assist Reprod Genet. 1995; 12: 35-40.

10. Scholtes, M.C.W., and Zeilmaker, GH. A prospective, randomized study of embryo transfer results after 3 and 5 days of embryo culture in vitro fertilization. Fertil Steril, 1996; 65:1245-1248.

11. Tesarik, J. Developmental failure during the preimplantation period of human embryogenesis. In van Blerkom, J. (ed.) The Biological Basis of Early Human reproductive Failure. Ox ford University Press, New York, USA, 1994; 327-344.

12. Olivennes, F., Hazaut A., Lelaider, C et al. Four indication for embryo transfer at the blastocyst stage. Hum Reprod, 1994; 9: 2367-2373.

13. Rieger, $\mathrm{D}$. The mesurement of methabolic activity as an approach to evaluating viability and diagnosing sex in early embryos. Theriogenology, 1984; 21: 138-149.

14. Rieger, D. Relationship between energy metabolism and development of the early embryo, Theriogenology, 1992; 37: 75-93. 